\title{
Denys Medvedovskyi
}

Postgraduate Student of the Department of Finance

SHEE "Kyiv national economic university named after Vadym Hetman", Kyiv, Ukraine

E-mail: medvedovskyidenis@gmail.com

ORCIDID: 0000-0002-5882-0269

\section{Smart technology based on financial content management}

\begin{abstract}
This article deals with the development of "Smart" technology, which is being developed on the basis of financial content management. Nowadays the evolution of smart technologies is impossible without the Internet and human intelligence. These two phenomena have become interconnected and formed a new definition, which was given the term "content management". As the world began to undergo social transformation in the digital age, finance has become an integral part of it. A completely new definition of "financial content management" has appeared, which was not previously known to mankind. In the period of global digitalization society needs the development characteristic of today. In the world of finance, this is accompanied by processes that have received the term "smart technologies". These smart technologies create new processes that are combined with the development of society, and also have a significant impact on finance as a separate industry. The article formulates the main idea of the future development of financial content management and the relationship of smart technologies with finance. It has been proven that smart technologies are an integral part of the development of the future society, and "financial content management" is a target component of finance.
\end{abstract}

\section{Keywords}

smart technologies; financial content management; content management

JEL: F65, F3

\section{Introduction}

Finances have undergone significant changes in the $21^{\text {st }}$ century. The development of digitization (digitalization) contributed to the formation of new forms and functions which are connected with finances. Taking into account these processes, the financial world has undergone some changes, namely, the emergence of smart technologies. They paved the way for an innovative form of organization of the functions of financial and economic systems and platforms. This background arose the question of a thorough study of the organizational function, which had not previously been studied in detail. Financial and economic corporations, which were previously engaged in organizational form, are currently unable to manage all available digital processes in the field of finance. All this prompts the development of new concepts based on the definition of "financial content management", which in the future may combine the functions of processes and technologies: product management, content management, computer network management. Since all smart technologies are based on marketing research strategies, as well as on all stages of the life cycle, from our point of view, the process of smart technology research based on financial content management is very appropriate. It is necessary to understand that the combination of these two very different industries is inevitable in the future. That is why it is important now to explore a separate state of smart technologies, information and innovation finance, as well as content management. It is worth focusing on the issue of multilateral business platforms, which are an inevitable consequence of the combination of "Industry 3.0" and "Industry 4.0". The use of technologies in the field of innovative finance is impossible without the available tools. The creation of such tools for public needs is possible only in terms of administrative decisions. The new infrastructure, which is 
actively developing in the market today, will not be able to work without effective solutions. With the development of Industry 4.0 and research in Industry 5.0, scientists have begun to offer many interesting solutions, but none of them take into account the fact that future financial development is impossible without the creation of new administrative and network technologies. Annual updating of existing solutions by updating various methods and techniques will not give a significant result. That is why it is important to offer the world a solution that does not yet exist. Modern economic literature offers many theoretical approaches to the future development of finance, as well as practical concepts for effective business creation based on it. A new form of business today is a rather slippery phenomenon. It is necessary to determine the vector, and then make an adjustment to the fact that all business today is subject to digitization. That is why it is important to explore the management function of smart technologies. Execution of this action is possible only taking into account administrative actions against the background of digital information. Despite the fact that all these processes are administrative, these actions can be performed only by financiers. This is subject to the processes and technologies involved in collecting, managing and publishing financial information in any form.

\section{Purpose of the research}

The purpose of the article is research and proposition to create tool technology which is based on financial content analysis. It can be based on the semantic core.

\section{Literature review}

It should be noted that the term "Smart" was first used in the work of Paul J Meyer in 1965, and later in the work of George Doran in 1981 [1]. Beside this, the term "content management" is well covered in the works of Boiko Bob in 2004 [2]. In general, many scientists in the United States have shown interest in content management as a separate definition. Among the studies that are devoted to finance and combined with the field of content management, the works of RockleyAnn [3], Hackos, JoAnn T. [4], Glushko, Robert J., Tim McGrath [5], Ferran, Núria, JuliàMinguillón [6] and others attract the most. Based on our research and conclusions, we offer a new world of technology unknown to mankind before. This technology can be used by world-class corporate executives, as well as government agencies for effective analysis of financial and economic calculations and payments. The technology we offer is an innovation that should be considered in Industry 5.0.

\section{Data and methodology}

\subsection{ANALYSIS OF AVAILABLE INFORMATION}

It should be emphasized that the innovative technologies that appear in the world today are developed on the basis of blockchain technology, the principle of which is divided into data recording and the combination of data recording blocks. All this happens on the base of network algorithms that contain certain blocks of information. Based on the fact that the world community shares this view, the financial community is interested in the fact that the circle of all these data is stored financial and analytical information. This can be information about certain agreements between several parties (smart contracts), information about the preservation of financial virtual assets (ICO), as well as information about any financial innovation product in the form of shares.

With the appearance of term IEO in 2019, cryptocurrency exchanges continue their active development. According to publicly available information on the Internet, the total cost of capitalization and the amount of cryptocurrencies in dollars is very large. It should be noted that the world community will not be able to influence the depreciation of cryptocurrencies. Examining indicators of price dynamics, it is necessary to emphasize that the world community has all the levers of pressure to change market capitalization. But this is not enough for global change. Instead, the states and the state system of developed countries are interested in the implementation of innovative financial instruments, arguing the opposite. In 2019 we saw a clear example of this, when the corporation Facebook developed the cryptocurrency Libra but could not withstand strong pressure from regulators.

Unfortunately, no technology has been invented today that can control smart and convenient financial services in the field of Fintech. However, it is worth noting that it is with the help of network algorithms based on technology from Google, which were launched in "Industry 3.0" it is possible to influence the optimization process. In our opinion, these processes are possible by minimizing costs based on content work.

\subsection{THE HYPOTHESIS PROPOSED BY THE AUTHOR}

We propose to develop a smart technology of financial content analysis based on the semantic core, which was launched during Industry 2.0 and Industry 3.0. Industry 4.0 has already developed unique dual scoring systems that offer customers digital financial products.

It is the smart technology of financial content 
analysis that will be able to become a part of Industry 5.0, as the very idea of Industry 5.0 can be based on technical applications that will work on more difficult levels and will interact both emotionally and logically.

The proposed technology will allow smart devices to perform certain functions. Analytical actions in smart technology can be programmed. Financial content management will be able to perform the function of a financial regulator in smart technology. Industry 5.0 and smart technologies based on financial content management will be combined on the interaction of artificial intelligence and technical processes. Based on the fact that the technology itself makes sense that any process will be associated with websites, the interface is a key feature of any mechanism.

\subsection{DATA EVOLUTION}

With the help of financial content management we propose to develop a mechanism for protecting financial flows, which can be analysed in smart devices. This script of the data security template will be able to process financial payments. This can be done on the basis of our proposed technology. In the future, we will be able to offer not only corporations but also web communities the technology of financial analysis based on content management if the proposed mechanism in the test mode gives a positive result. The proposed technology can be used to verify financial information and financial calculations in web systems. We propose to develop a script that will be responsible for the security of financial data using the cloud system. Since the content chain cannot be verified, companies and corporations dismiss directors and department heads [9]. In the context of the fact that society and information technology are evolving, it is necessary to pay attention to the development of completely new products.

The evolution of the World Wide Web (Web) has evolved from Web 1.0 to Web 5.0. Despite this, unfortunately, no technology has been invented that will allow the use of innovative financial instruments in smart technology. In terms of the fact that Web 5.0 plans to be developed on the basis of artificial intelligence and "telepathic web", it is worth noting that our proposed technology based on the semantic core will allow the analysis of financial payments. The essence of the technology is precisely the analytical function, which will be used to collect and analyze financial information. In 2020 humanity has begun to pay active attention to the web generation, and mechanisms such as web pages have become integral helpers. In the context of this, there are innovative types of payments that are made using microchips. We believe that technology will develop in this direction in the future. It is advisable to pay attention to smart devices, which will be equipped with artificial intelligence, the Internet, innovative financial instruments, as they will be controlled by mankind.

Therefore, we believe it is advisable to implement smart technology of financial analysis, which will check financial payments and economic errors. Our proposed technology can be used by various smart devices. Highly intelligent interaction of all links and processes in this mechanism will allow the financial regulator to check all financial and economic processes. As practice has shown, the most powerful financial regulators, including the US financial regulator, opposed the implementation of the cryptocurrency Libra on Facebook. Based on this, we can assume that with the development of all financial and economic units, as well as smart processes, global governing bodies have not been able to develop technology that can control all financial and economic processes associated with the verification of digital financial and economic information. Mankind has faced the problem of untimely mastery of information (for example, public authorities), which has given a crack for future developments in this direction.

We believe that global concerns and global organizations cannot be wrong. The following companies can be distinguished among such corporations (rating was created on the basis of market capitalization) (Figure 1):

We consider it appropriate to involve financial content management in the chip systems of all smart devices. Given that all smart devices have their own smart technologies, the use of smart technology based on financial content management is appropriate for smart devices, which will be developed in 2020-2030.

The involvement of such technology may seem interesting for global corporations, including debit electronic payment services. An example of such a system may be PayPal Inc. In addition, interest in such technology can be shown in companies that offer their services in the field of online auctions, as well as online stores, for example, eBay Inc. It is worth noting the fact that the technology can be involved in world-class e-commerce platforms, including Amazon Inc. It should also be noted that based on the fact that the technology is centered on a digital mechanism based on semantic core technology, the greatest interest in the technology may be shown by corporations engaged in public cloud computing, the main one being Google.

Since each of the above world-class companies is interested in developing their own payment system, which will operate cryptocurrency, our proposed technology of financial and content analysis can improve the performance of companies and their financial performance.

We are also convinced that innovation in the field of smart technology is appropriate as of 2020-2025, because the relationship between innovation and financial efficiency is due to the 


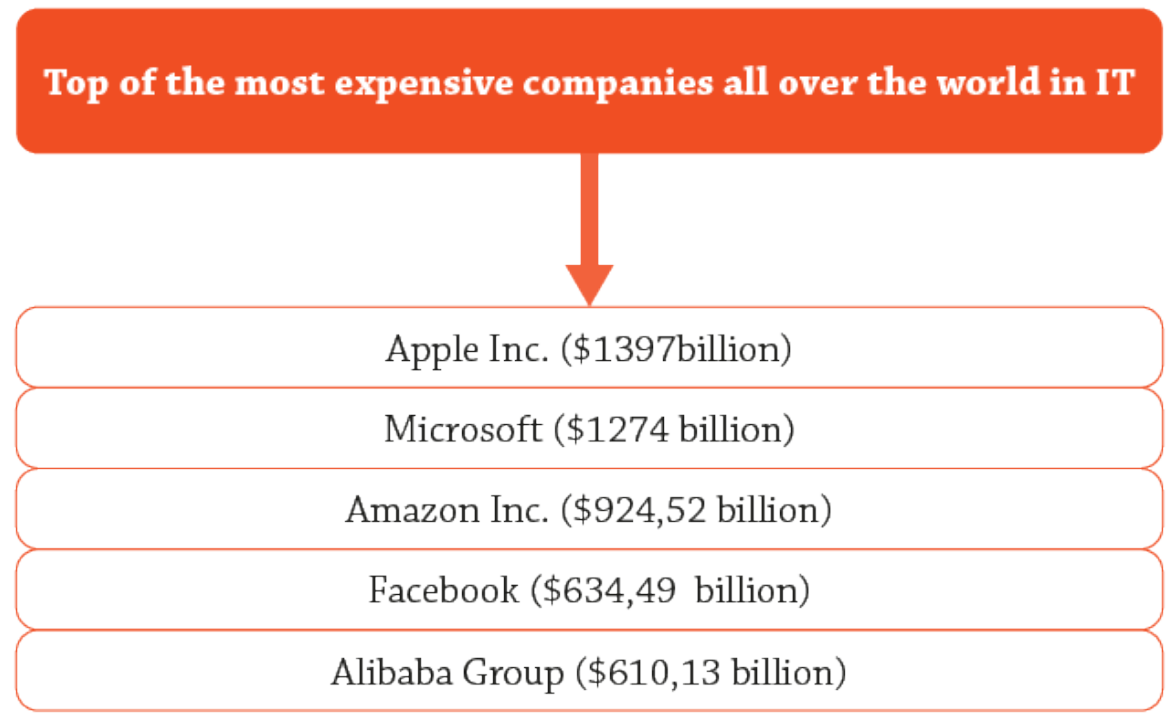

Figure 1 Top of the best significant companies in orchestrating techno-financing sphere

image of many companies.

The Industrial Revolution 4.0 proved to the world that the trend of digitalization will develop, and information and communication technologies (ICT) are the basis of the concept of the industrial revolution [7].

The smart technology of financial content analysis can be linked to research that aims to identify content in specific areas. Some researchers have already proved the fact that content analysis is very relevant in many modern areas, a clear example of which is smart contracts [8]. It should be noted that many empirical studies have not yet been conducted, because the use of smart technologies in full have started recently.

The smart technology of financial content analysis can work on the basis of semantic search. This technology must take into account:

- Information hash algorithm;

- Location;

- The purpose of the transaction;

- Number of variations:

Based on the fact that the purpose of semantic search is to determine the user's request, the purpose of our proposed concept is to preserve the transparency of transactions, as well as various payments, using smart technology that will be implemented in smart devices.

Our proposed concept can be considered as an algorithm of actions that are aimed at protecting financial transactions for smart technology.

\section{Results}

Semantic technologies help search engines understand data. It is known that this technology uses RDF (Resource Description Framework) and OWL (Web Ontology Language).

In turn, our proposed smart technology based on content analysis (STBOCA) will be able to describe the analysis of data on financial transactions between financial products and their categories. This technology with financial data provides a significant advantage of using any product through online transactions. This will allow you to use different technical devices (of different shapes) remotely from them without controlling them. In software terms, the technology will be able to remotely encode data files, financial chain and code in the microchip of the device. This will allow technical devices that will house the technology (STBOCA) remotely based on content analysis to perform operations using the semantic core.

The proposed technology must be considered in terms of innovative progress in the field of finance, because a lot of financial transactions are already made today with the help of smart devices. In our opinion, it will be possible to analyse financial data in text format with the help of our proposed technology. This is a fairly new form of analysis that can be combined with software. That is why we focus on smart technologies.

In the era of information technology, our proposed technology can be considered at the global level. Based on the fact that the algorithm of actions is mainly based on the semantic core, from our point of view, the technology of financial content analysis will be able to make comparisons with financial and economic information. When considering this issue, it is necessary to focus on data protection. Here are some examples of where our proposed technology can be actively used. 
Example 1. A significant push in the fintech sector occurred only after significant funding, namely in 2013 [10]. The active growth of investments in the financial sector has shown that the financial and economic direction in the information technology sector is the future. That is why, in our opinion, we should continue to develop the financial and economic direction and carefully develop it. It is also expedient that in the field of financial technologies significant importance is attached to neobank. Based on the fact that neobank is an online bank built on technological platforms [11], innovation infrastructure is one of the priority areas of neobank development. With the help of financial content analysis, you can perform data analysis, develop verification algorithms for all banks, as well as with the help of smart technologies in finance to conduct an audit.

Example 2. Innovative development in the field of finance is impossible without ensuring the development of SupTech \& RegTech [12]. In the financial markets sector, certain tasks are undertaken by both government agencies and financial market participants. This definition is now shared in RegTech and SupTech [13]. RegTech technology is a comprehensive approach to measures to reduce the cost of financial services in the financial market. In addition, this technology is a tool for the expenditure side of government regulators. Today, RegTech technology mostly operates in countries with the most powerful developed financial system, such as the United States and the United Kingdom. In the field of finance, regulators are responsible for innovative technologies, which are commonly called SupTech. SupTech technology is responsible for optimizing digital data and innovative financial instruments. Such technologies include BigData technology, cloud technologies and structural data analysis. Innovative financial infrastructure cannot be handled by existing technologies. That is why our proposed technology of financial content analysis will be able to check for plagiarism all information sources with financial information. This will significantly improve the development of individual departments in different countries. This will give a boost in the geopolitical arena, namely, weak countries will not be able to develop them.

In our opinion, with the help of semantic core technology it is possible to create significant financial instruments and levers of influence in the future. Today, society underestimates the work of search algorithms, which is why society does not pay much attention to this. But, given that in the future the essential importance of the world community is focused on the development of information financial technologies, which are combined with finance, we consider it appropriate to consider indirect innovative technologies based on the semantic core.

It is also important that in smart technology it is possible to implement search algorithms of robots on the basis of our proposed smart technology of financial content analysis (STBOCA). The technology can be developed on the basis of a software product that can be downloaded to the device as separate software. It will be possible to use such technology at the state level.

The example of Austria in 2014 showed that the use of SupTech technology, launched by the National Bank of Austria, justified the efforts of the government and scientists. Austrian technology [14], which works on the ABACUS platform, forces banking institutions to send all information on financial agreements, deposits and loans from all institutions to the state. All this happens in a standardized form. The process takes place using "base cubes". When receiving a request for information from the regulator, the platform forms the so-called "smart cubes" of data. They are information aggregated in a form that meets the objectives of the regulator's analysis.

We believe that smart technology based on financial content analysis can be used by financial content managers. They must process information using a CMS system (data management system).

\section{Conclusion}

We suggest to consider the possibility of implementing smart technology of financial content analysis in "Industry 5.0", which can be managed through content management.

This technology will significantly improve the work of financial institutions in the world. This will allow the development of financial instruments and their future integration into the financial system. The introduction of such technology in the world will allow to expand the global financial space. Moreover, the experience of developed financial communities proves that many financial institutions are interested in innovative financial technologies [15]. That is why we believe that our proposed technology can be considered as a technological intermediary between corporate financial management, analysis and verification of financial information and reporting. This mechanism can be considered in the future as a separate model that can operate as a separate state department.

The development of various technologies based on content analysis, which is based on the semantic core, is inevitable. That is why we propose to consider and in the future develop a technology that can become a cost-effective factor for analysis of various processes.

In our opinion, the creation of such technology can be interesting not only for the target audience, which is engaged in financial and economic 
activities, but also for companies engaged in auditing. Based on this, we believe that customers will be able to track digital content and track financial information. The technology, which is based on financial and analytical activities, will be of interest to government organizations. The government agencies will be able to verify information with the help of technology. Also with the help of the proposed technology it will be possible to analyse financial offenses that occur on the Internet. This will improve the functions of government agencies, because with the help of financial content management, financiers and financial content managers in the future will be able to cope with various difficulties in their work, which will be manifested in them digitally.

\section{Acknowledgment}

The article is written in the framework of the study "INNOVATIVE TECHNOLOGIES OF THE FINANCIAL MARKET IN THE CONDITIONS OF INFORMATION ECONOMICS: A NEW PARADIGM OF DEVELOPMENT".

\section{References}

[1] Doran G T 1981 There's a S.M.A.R.T. way to write management's goals and objectives Management Review 70(11) (AMA FORUM) 35-6

[2] Boiko B 2004-11-26 Content Management Bible Wiley p 1176 ISBN 0-7645-7371-3

[3] Rockley A 2002-10-27 Managing Enterprise Content: A Unified Content Strategy New Riders Press $\mathrm{p}$ 592 ISBN 0-7357-1306-5

[4] Hackos JoAnn T 2002-02-14 Content Management for Dynamic Web Delivery Wiley p 432 ISBN 0-47108586-3

[5] Glushko R J, McGrath T 2005 Document Engineering: Analysing and Designing Documents for Business Informatics and Web Services MIT Press p 728 ISBN 0-262-57245-1

[6] Ferran N, Minguillón J 2011 Content Management for E-Learning Springer p 215 ISBN 978-1-44196958-3

[7] Alaloul W S, Liew M S, Zawawi N A B, Kennedy I B Industrial Revolution 4.0 in the construction industy: Challenges and opportunities for stakeholders Ain Shams Engineering 11(2020) 225-30 E-source: https://reader.elsevier.com/reader/sd/pii/ S2090447919301157?token=9011AF26F397C7653BD49F346A14B71CD0431C5FD226692A83B 2C56A4EE26C769B948385A27AF844E4C5437CD2C82

[8] Schmitt G, Strauss C, Schaffhauser-Linzatti M 2019 Smart Contracts and Internet of Things: A Qualitative Content Analysis using the Technology-Organization-Environment Framework to Identify Key-Determinants Procedia Computer Science 160 189-96 https://doi.org/10.1016/j. procs.2019.09.460

[9] Bernard T S, Cowley S 2017 Equifax breach caused by lone employee's error, former c.e.o. says E-source: https://www.nytimes.com/2017/10/03/business/equifax-congress-data-breach:html (Last checked: 01.12.2018)

[10] Pochenchuk H M 2007 Financial Technologies: Development and Regulation Economy and Society 13(2007) 119 E-source: http://economyandsociety.in.ua/journal/13_ukr/200.pdf

[11] Savchenko T H, Tatark A V 2018 Current trends in the development of financial technologies. Bulletin of SSU. Economics Series 4 E-source: https://visnyk.fem.sumdu.edu.ua/media/ attachments/2020/03/04/8-56-64.pdf

[12] Institute of International Finance March 2016 RegTech in Financial Services: Technology Solutions for Compliance and Reporting 